\title{
Analysis of Combustion Noise in Diesel Engines
}

\section{Sunny Narayan*}

Phd Candidate, Mechanical Engineering Department, University of Roma Tre, Via Della Vasca Navelle, Rome,ITALY-8400146

Sunny Narayan is currently a phd candidate in the mechanical engineering department in the university of Roma Tre. He holds a bachelor's degree in mechanical engineering from the National Institute of Technology, Srinagar in India and a masters degree from University Of Bristol (U.K.).His area of research include Noise, Vibration and Harness in Combustion Engines. He has been reviewer of many reputed journals including International Journal Of Acoustics and Vibrations. He is member of ASME \& INCE, USA \& has several peer publications to his credit.

Abstract: Injection process in diesel engines is a key to control engine performance parameters such as torque and power as well as to control noise and emissions from engine. Condition monitoring of injector is an important methodology for obtaining information about fuel injection process. However it is difficult to monitor the injector motion using air borne engine acoustic signals. In this work adaptive filtering has been used to study the injector impacts using condenser microphone located at a distance of $0.25 \mathrm{~m}$ from the engine rig on a array structure. The data obtained was filtered and processed in MATLAB 7 software. Various injection pressures were used and time frequency Wigner Ville Function was used to study the injector impacts.

Keywords: Engine Noise; Vibrations; Condition Monitoring.

\section{Introduction}

Study involving various improvements in diesel engine have been necessiated to match NVH comfort standards.Fuel injection system management is one of such method which has a direct impact on engine performances as depicted in [1]. Amount of fuel injected, Injection pressure \& Valve operation timings are key to condition monitoring methods in engines. These parameters must be optimized in order to meet emission standards and increase power output [2]. Previous work involving injection monitoring has been focussed on noise and vibrations generated by fuel pump and fuel lines [3]. In diesel engines a small amount of fuel of order $15 \mathrm{mg}$ moves in a short time interval of 1-3 milliseconds inside the engine which involves quick opening and closing of injectors. As a result the injector noise radiated is a short tickling noise with a broad frequency bands. The noise is radiated from the injector and transmitted to engine surface. The opening noise of injector occurs due to moving mass hitting the upper stop whereas the closing noise occurs due to moving mass hitting the seat. The signal obtained from engine is corrupted by background noise Active noise filteration \& coherent filtering can be used to improve the sound to noise ratio of frequencies attributed to room resonance conditions. Adaptive filtering was used to enhance the transient components of signals and finally Wigner Ville distribution was used for better localization 
of events. Noise emitted from engine consists of several components which include combustion noise, motion based noise,Flow noise etc. Table no 1 shows various possible sources of noise in a diesel engine along with their excitation forces. Combustion noise is produced due to rapid fluctuations of gas pressures in combustion chamber which also causes resonace of engine structure. The structural vibrations are also dependent upon engine type, hence overall virbation levels from an engine is a function of cylinder pressures $\mathrm{p}(\mathrm{t})$ \& impulse response of engine $h(t)$ and hence can be respresented as [4]:

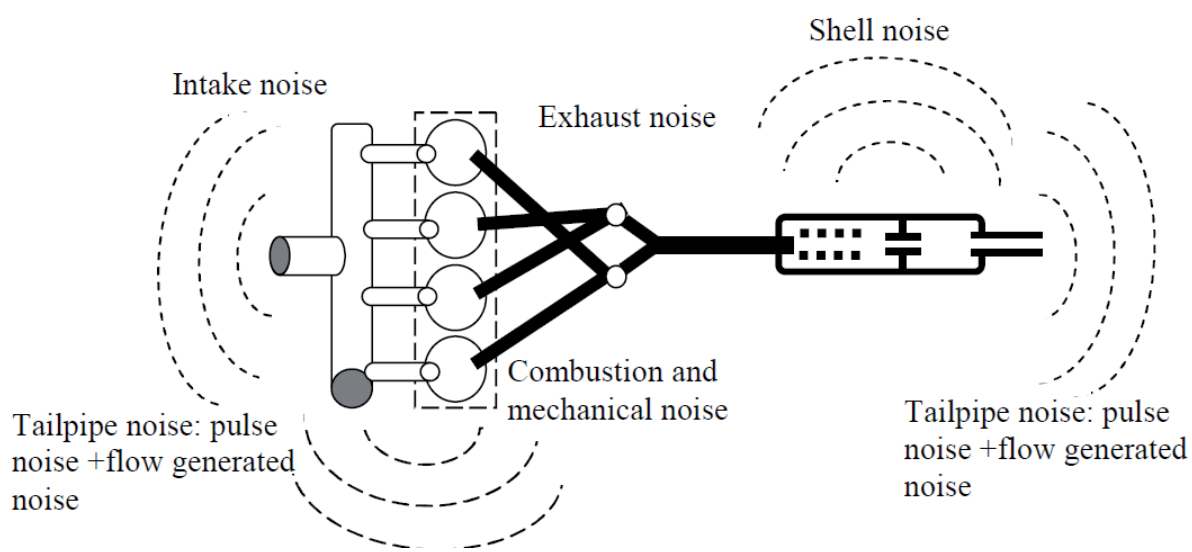

Fig. 1: Engine Noise Sources.

Table 1: Engine Excitation Forces.

\begin{tabular}{|l|l|l|l|}
\hline Source & Force & Transmission & Noise Emitter \\
\hline Combustion Noise & Rapid Pressure change & $\begin{array}{l}\text { Cylinder head,Piston, } \\
\text { Connecting Rod }\end{array}$ & $\begin{array}{l}\text { Engine Block, Cover, } \\
\text { Manifolds }\end{array}$ \\
\hline Mechanical Noise & $\begin{array}{l}\text { Fuel pump, Injector } \\
\text { Impacts, Valve Motion }\end{array}$ & $\begin{array}{l}\text { Cylinder walls, Piston } \\
\text { Connections }\end{array}$ & Sump, Block \\
\hline
\end{tabular}

Cylinder pressure causes the piston to move from TDC to BDC. During this motion the gap between cylinder walls and piston causes the piston to strike the walls producing slapping noise. An engine has both rotary and reciprocating parts producing noise and hence various signals are obtained from the engine under test. Based on the above discussion the overall microphone signal $\mathrm{s}(\mathrm{t})$ can be decomposed into three major contributions as below $[5]: \mathrm{s}(\mathrm{t})=\mathrm{s}_{1}(\mathrm{t})+\mathrm{s}_{2}(\mathrm{t})+\mathrm{s}_{3}(\mathrm{t})+\mathrm{n}(\mathrm{t})$

Where: $\mathrm{s}_{1}(\mathrm{t})$ is the narrow band frequency content which is integral multiple of fundamental rotation speed, $\mathrm{n}(\mathrm{t})$ is random noise dependent upon type and microphone location, $\mathrm{s}_{2}(\mathrm{t})$ is non harmonic frequency band and $\mathrm{s}_{3}(\mathrm{t})$ represents noise due to sudden impacts.

\section{Adaptive Filtering}

Adaptive filtration method is a powerful tool to analyze signals in case where overlap between noise and signals occurs and hence conventional filters do not perform well. Adaptive filters adjust the coefficient according to error signals. There are several algorithms to adjust the filter coefficients, commonly used being least mean square method.

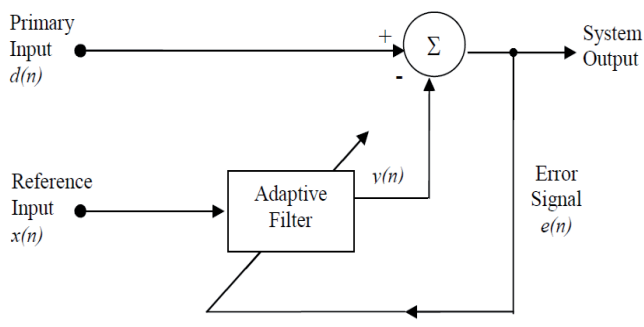

Fig. 2: Adaptive filter.

The reference signal is filtered and subtracted from primary signal to produce output signal. The 
filtering is based on least squares method, where $\mathrm{x}(\mathrm{n})$ is reference signal free from noise and $\mathrm{d}(\mathrm{n})$ is corrupted signal. The adaptive filter is based on least mean square method. Another method named adaptive self tuning is shown in next figure which is based on delayed version of input signal. These filters are based on Widrow's LMS method [6]

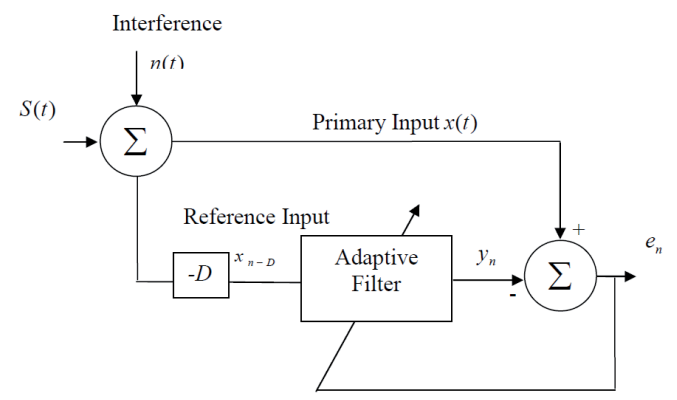

Fig. 3: Self tuning filter.

It is difficult to extract low energy vibrations caused by needle of injectors as other sources of noise dominated in the extracted noise signals. Hence adaptive filtering method is needed to suppress other noise sources.

\section{Experimental Section}

Experiments were carried out on a lombardini LDW442CRS common rail double direct injection engine system having specifications as given in the Table no 1. A fully opened electronic control unit connected to computer was used to manage the injection system with aim to control operational parameters. The engine was coupled with an a synchronous motor of SIEMENS $1 \mathrm{PH7}$ make thus allowing to control speed and load. A Bruel and Kjaer free field microphone of 4939 type with a 2670 type preamplifier was used to obtain acoustic data. This engine test rig has a Piezo electric type Kistler 6056A make pressure transducer for in cylinder pressure measurements and an optical crank angle encoder of AVL 364C make for detection of TDC position as well as engine speed. The given system can do maximum of 2 injections per cycle. All signals were simultaneously acquired by $\mathrm{NI}$ boards of 6110 type (for analog type) \& 6533 type (for optical encoder signals) using LabVIEW 10 software. During the tests the sampling rate was varied in order to guarantee a resolution of $0.25^{\circ}$
CAD. The engine was operated at speeds of 1600 RPM and various loaded and motored conditions as seen from Table no III \& IV.

Table 2: Specifications of Engine

\begin{tabular}{|l|l|}
\hline $\begin{array}{l}\text { Stroke } \\
\text { Bore } \\
\text { Displaced Volume }\end{array}$ & 60 \\
\hline $\begin{array}{l}\text { Torque } \\
\text { POWER }\end{array}$ & $60.6 \mathrm{~mm}$ \\
\hline Compression Ratio & $250 \mathrm{~cm}^{3}$ \\
\hline
\end{tabular}

Table 3: Experimental Data Acquired.

\begin{tabular}{|l|l|l|l|}
\hline Case & Load & RPM & Prall(BAR) \\
\hline B1 & $50 \%$ & 1600 & 508 \\
\hline B2 & $100 \%$ & 1600 & 714 \\
\hline B3 & $0 \%$ & 1600 & - \\
\hline
\end{tabular}

Table 4: Injection Parameters.

\begin{tabular}{|l|l|l|l|l|}
\hline Case & Qpre & \multicolumn{1}{l}{ Qmaln } & \multicolumn{1}{c|}{ SOlpre } & \multicolumn{1}{c|}{ SOlmain } \\
\hline B1 & 1 & 6.3 & $19.9^{\circ}$ & $5.09^{\circ}$ \\
\hline B2 & 1 & 13.8 & $14.6^{\circ}$ & $6.29^{\circ}$ \\
\hline B3 & - & - & - & - \\
\hline
\end{tabular}

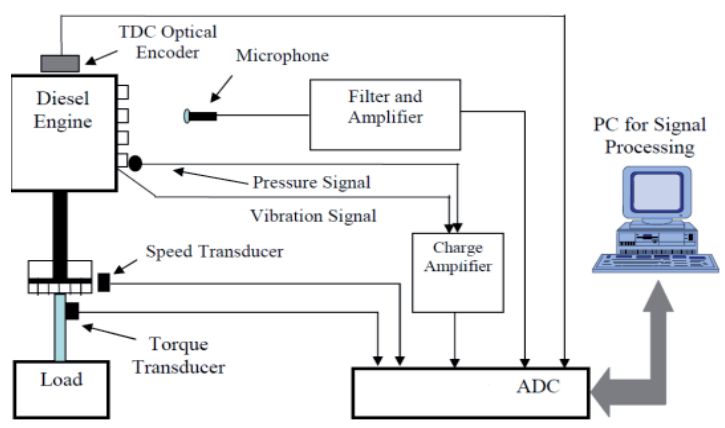

Fig. 4: Engine Test Rig.

\section{Results and Discussion}

The pressure in combustion chamber of a diesel engine has been studied extensively to separate combustion induced vibrations, injection events and other noises have been accurately isolated and filtered out. Figure no 5 shows the pressure crank angle trace for the given testing conditions.

In case no combustion event occurs the curve is labelled as motored condition. If fuel is injected 
some degree before TDC, there is a period of ignition delay which is followed by rapid rise in cylinder pressure. Rapid rise in pressure generates high frequency components as shown in figure no 6 .

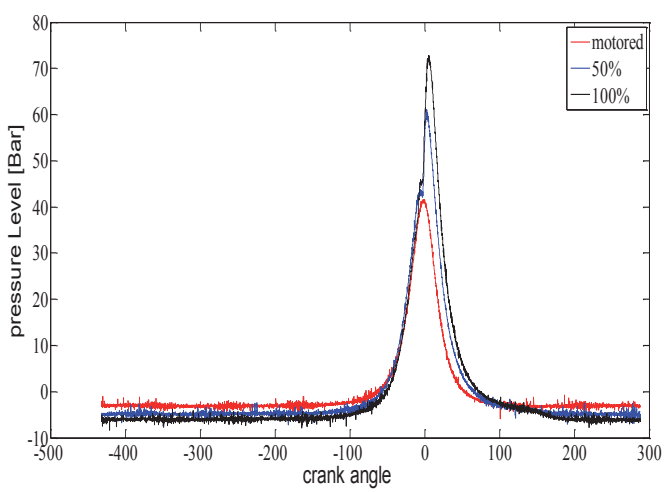

Fig. 5: Pressure Crank angle curve.

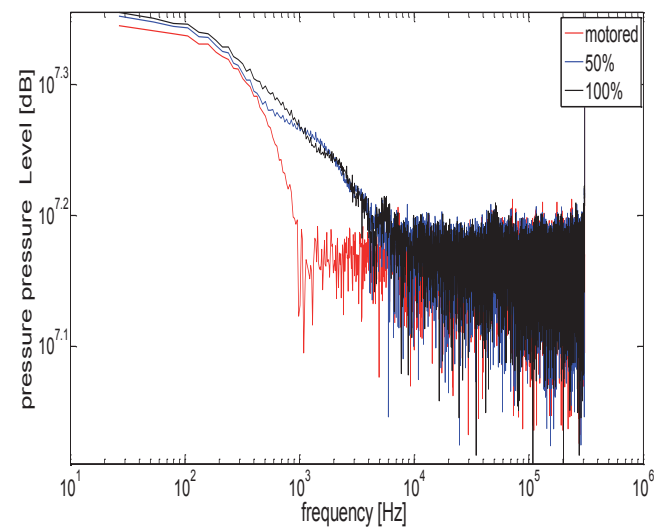

Fig. 6: Spectrum of Cylinder Pressure.

A rapid fluctuations in pressure was observed around $5 \mathrm{KHz}$ frequency which denotes the onset of combustion process. Increase in high frequency contents is due to motion of piston towards TDC after fuel has been injected. The spectrum drops off rapidly initially indicating very less high frequency energy. All the testing conditions showed the same trends. The acquired signals are seen in figure no. 7-10. As seen from plots a slight drop in injection pressure was observed before onset of combustion around $5^{\circ}$ Before TDC.

The induced noise levels are superimposed on injector pressures for the two firing conditions for two complete revolutions of crank shaft in next graphs.

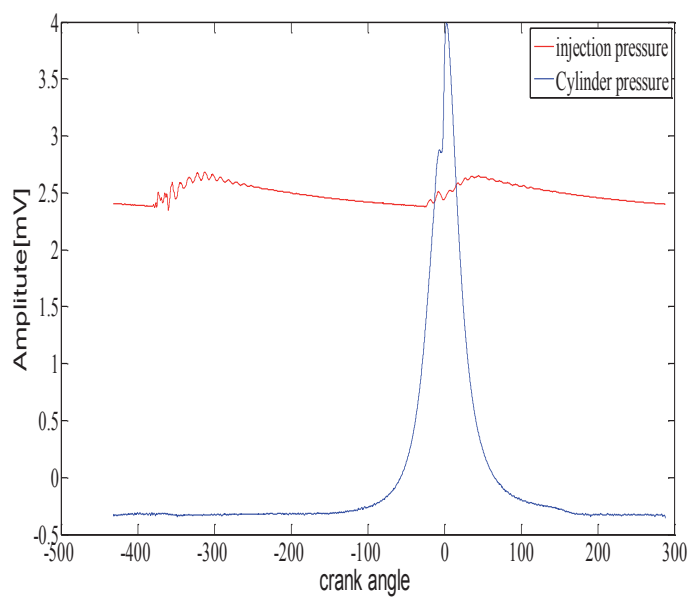

Fig. 7: Superimposition of Parameters Case (B1).

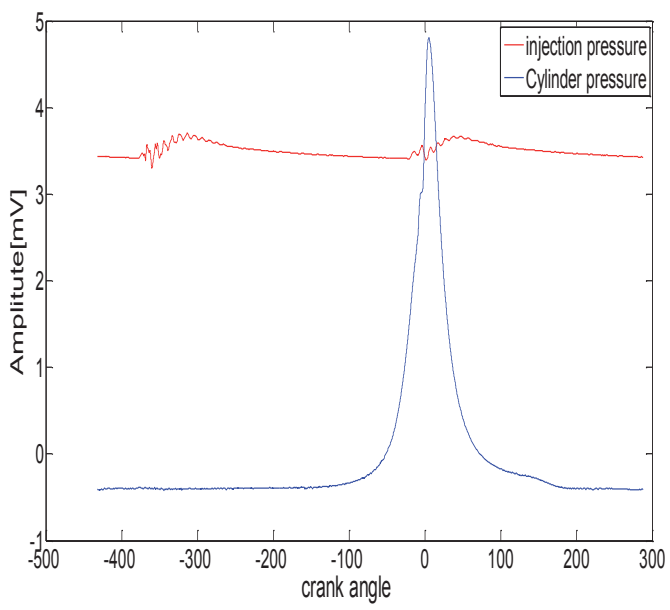

Fig. 8: Superimposituon of Parameters Case (B2).

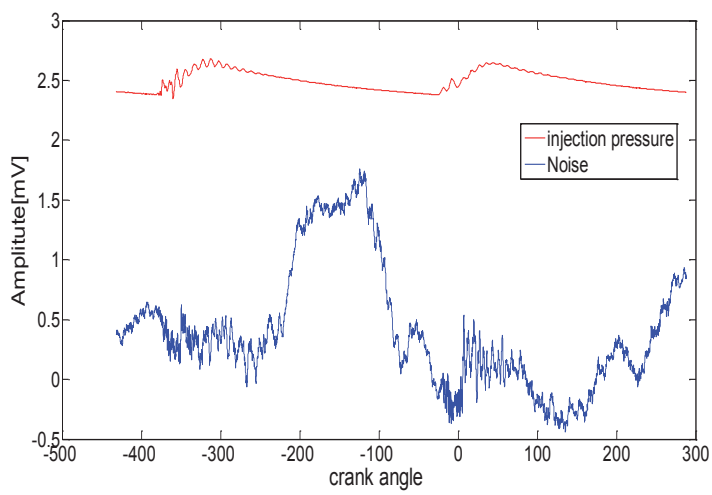

Fig. 9: Superimposituon of Noise and injection pressures Case (B1) 


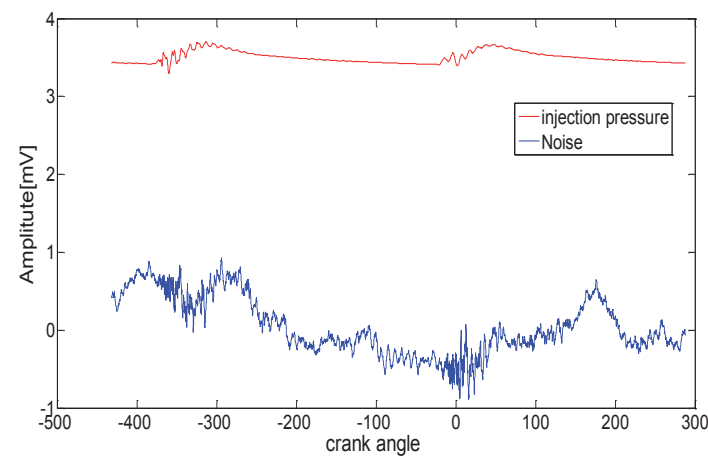

Fig. 10: Superimposituon of cylinder and injection pressures Case (B2).

It is complicated to extract all events as numerous wave forms superimpose on each other [6]. Hence Time-Frequency plots were plotted for detection of injection events. The results are shown in figures 11-13.

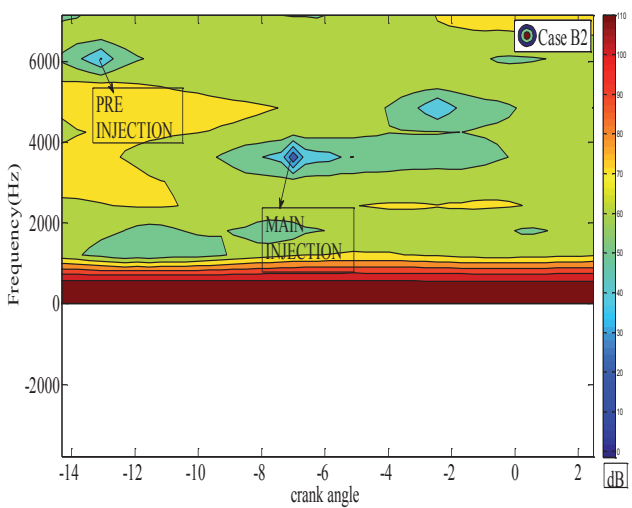

Fig. 11: STFT plot Case (B2).

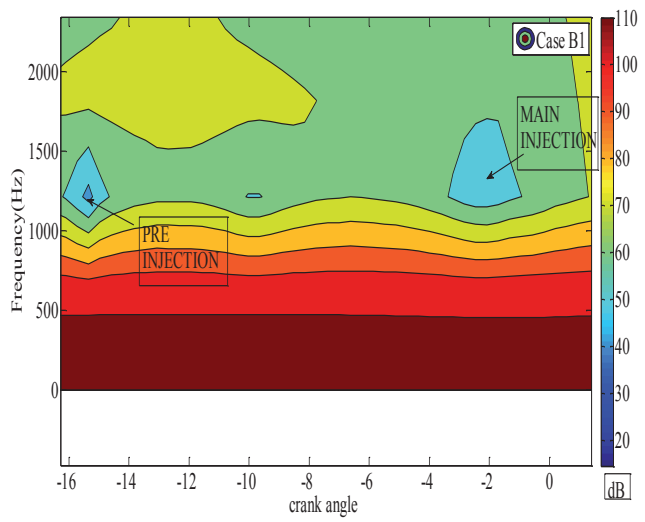

Fig. 12: STFT plot Case (B1).

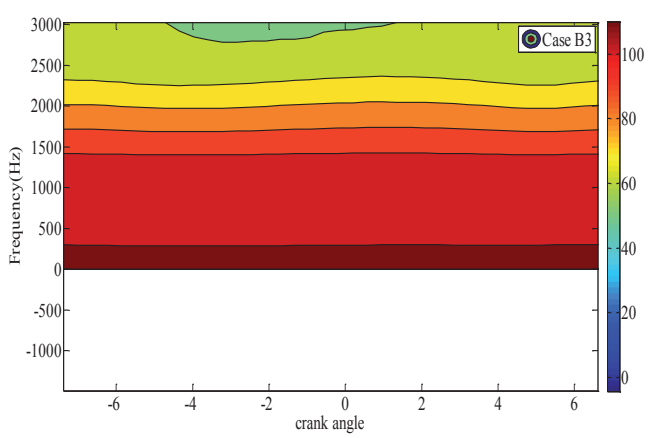

Fig. 13: STFT plot Case (B3)

As evident from these plots the injection events had frequency in range 1000-6000 Hz, however majority of events are dominated by combustion process. In order to extract more information about injection events, signals were double filtered using a band pass filter. First stage used LMS algorithm to remove harmonic components whereas the second stage used normalized LMS method. Graphs from 14-19 Show results of filtered signals.

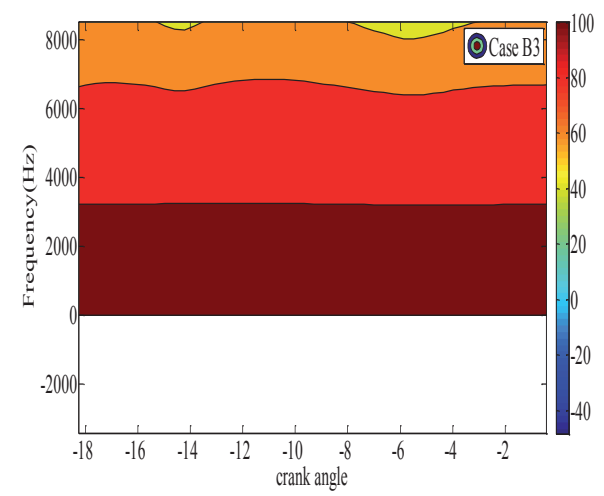

Fig. 14: Stage 1 filtered STFT (B3).

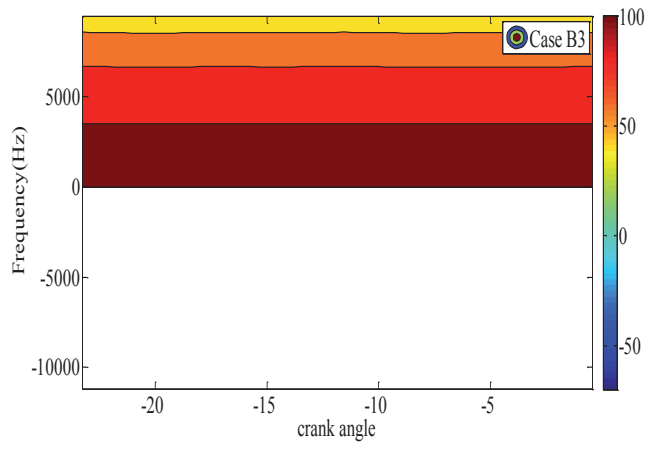

Fig. 15: Stage 2 filtered STFT (B3). 


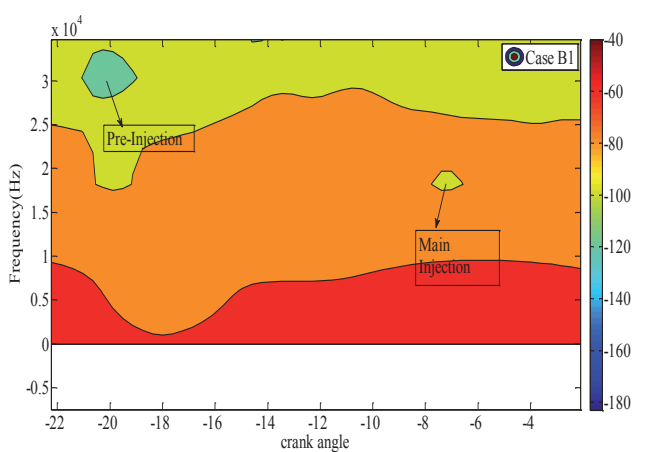

Fig. 16: Stage 1filtered STFT (B1).

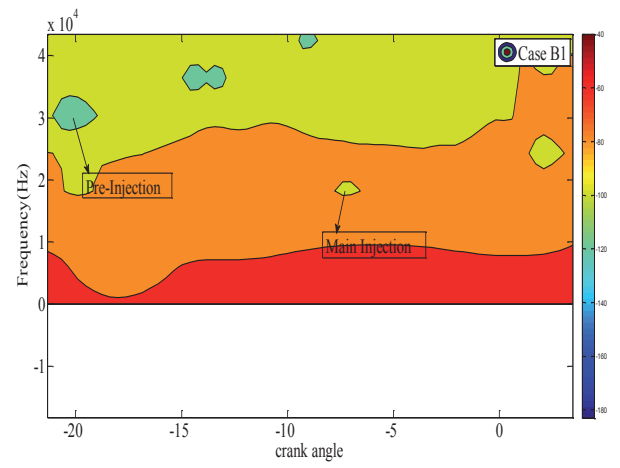

Fig. 17: Stage 2 filtered STFT (B1).

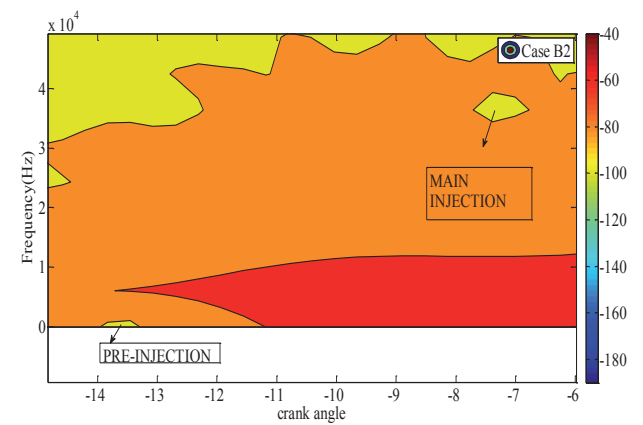

Fig. 18: Stage 2 filtered STFT (B1).

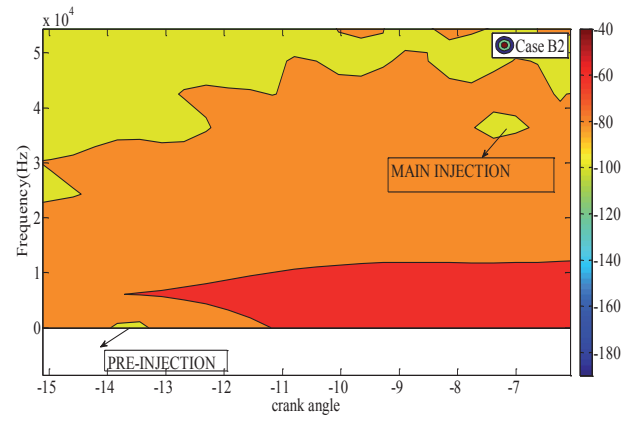

Fig. 19: Stage 2 filtered STFT (B2.)
As evident from from these plots the needle impacts before TDC become clearer. By increasing amount of fuel stronger impacts are more evident. Stiffness of valve spring also plays a role in injection process. Any fall in stiffness can cause delay in injection and hence combustion process degrades. Figure 20 shows the normalized values of energy of noise signals computed for the given test conditions.lt is clear that energy values fall with injection pressure.

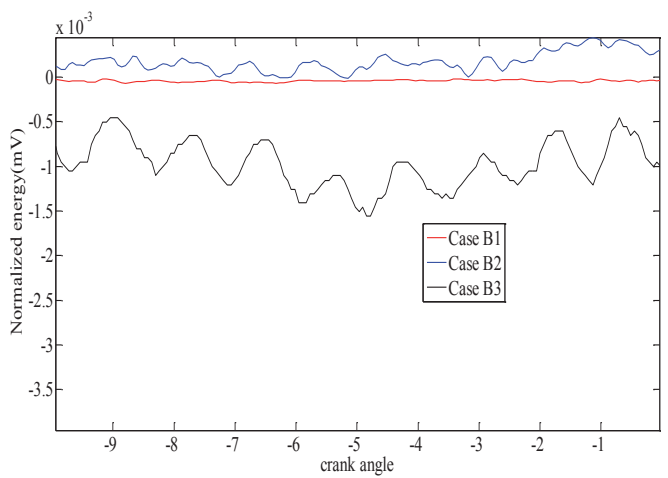

Fig. 20: Energy values of signals.

\section{Conclusion}

Filtering method is a promising method to detect and analyze various events taking place in a diesel engine. Frequency analysis of diesel engines show the dominance of fundamental firing frequency and its harmonics. Low Frequency bands are dominated by combustion noise and careful filtering needs to be done in order to extract information about other events occurring in engine. The adaptive filtering method used in this article is an excellent approach to detect small changes in injector faults hence a good tool for condition monitoring. It can be further used to enhance noise impulse due to valve and piston operations.

\section{References}

[1] A. Parlak, H. Yasar, C. Hasimoglu, A. Kolip. The effects of Injection Timing on NOx Emissions of a Low Heat Rejection Indirect Diesel Injection Engine. Applied Thermal Engineering, Volume 25, 2005, 3042-3052.

[2] K. Purushothaman, G. Nagarajan Effect of Injection Pressure on Heat Release Rate and Emissions in Cl Engine Using Orange Skin Powder Diesel Solution Energy Conversion and Management 2009. 50: p 962-969.

[3] F. Gu, A. D. Ball, Diesel Injector Dynamics and Estimation 
Injection Parameters from Impact Response. Part 1: Modelling and Analysis of Injector Impacts. Proc Institution of Mechanical Engineers. Proc. Inst. Mech. Eng., Part D (J. Automob.Eng.) 1995, Vol. 210, pp. 293-302.

[4] M. Ishihama, Improving Diesel Engine Noise and Vibration Assisted by Time Domain Subjective EvaluationTechnique, Kanagawa Institute of Technology, Atsugi, Japan. 1997.

[5] S5. A. Albarbar, F. Gu, A. D. Ball,A. Starr,Acoustic Monitoring of Engine Fuel Injection Based on Adaptive Filtering Techniques,Applied Acosutics,Vol 71,issue 12 ,December 2010.

[6] S. Haykin, Adaptive Filter Theory. New Jersey: Prentice-Hall; 2002, ISBN 978-0-12-374538-5.

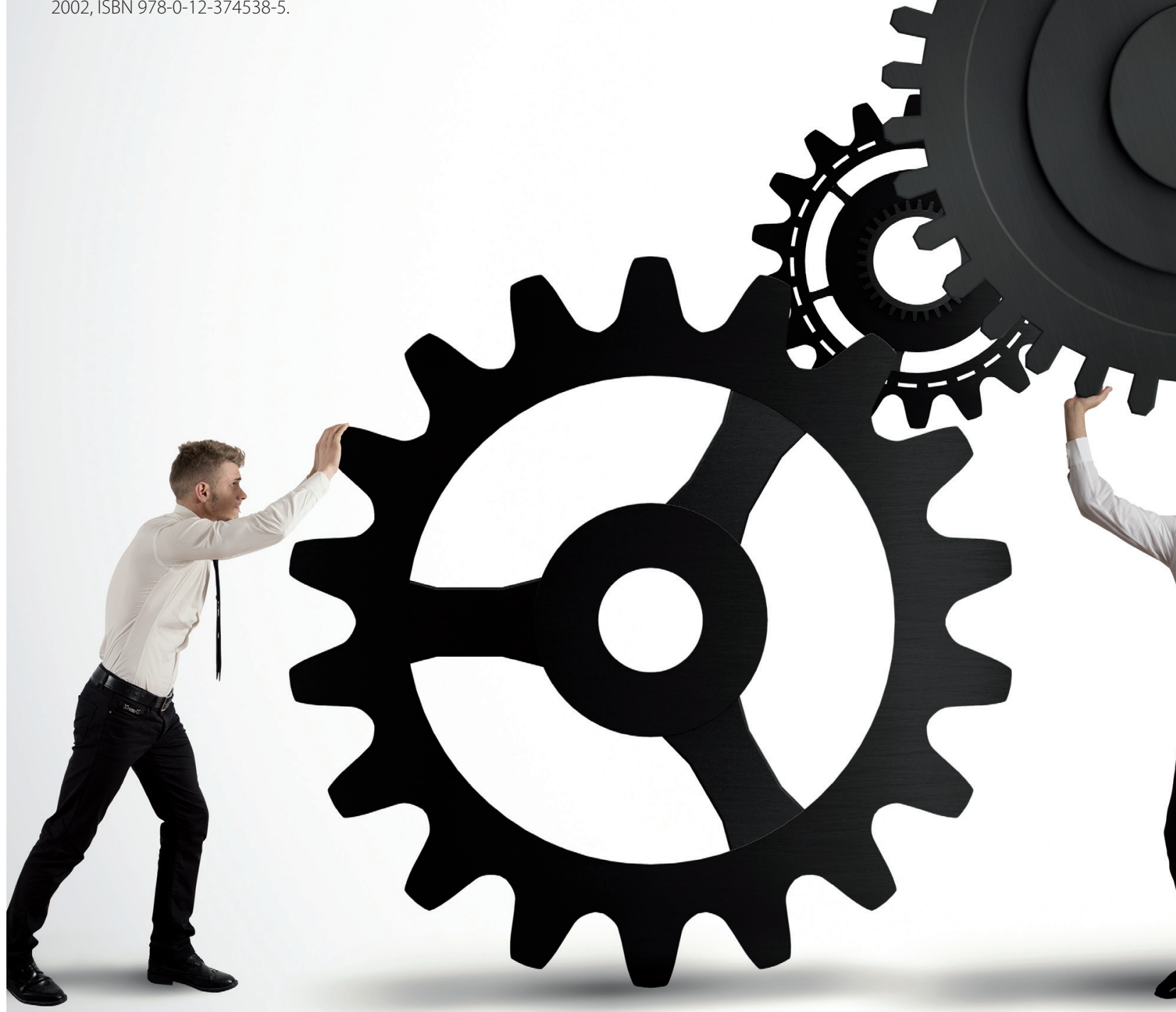


